\title{
Neuroscience, accountability and individual boundaries
}

\author{
Amedeo Santosuosso ${ }^{1,2}$ and Barbara Bottalico ${ }^{2,3 *}$ \\ Court of Appeal of Milan, Milan, Italy \\ 2 Interdepartmental Research Center European Centre for Life Sciences Health and the Courts, University of Pavia, Pavia, Italy \\ ${ }^{3}$ Fondazione Istituto Di Ricovero e Cura a Carattere Scientifico Policlinico San Matteo, Pavia, Italy \\ ${ }^{*}$ Correspondence: dr.bottalico@gmail.com
}

\section{INTRODUCTION}

Cognitive neuroscience holds the promise of explaining operations of the mind in terms of the physical operations of the brain. It is claimed that brain imaging techniques now allow the discovery of neurophysiologic markers for almost any kind of behavioural phenotype, normal or pathological, both at explanatory and predictive level. Since early 2000, law has taken part in this debate within the parameters of neuroethics, a new interdisciplinary field "at the intersection of the empirical brain sciences, normative ethics, the philosophy of mind, law and the social sciences of anthropology, economics, psychology and sociology" (Glannon, 2007).

When issues like these are discussed in legal contexts a normal first reaction is to wonder whether a more complete understanding of the neural mechanism for voluntary decision-making might undermine the legal notion of accountability. Would brain scans that reveal a brain feature correlated, even weakly, with a propensity for violence, influence a court's sentence? Will brain imaging subvert the current nosography of mental diseases? Is free will still alive?

In this paper, after a short presentation of these issues, we maintain that it is neither exhaustive, in theoretical terms, nor productive to face the new reality in this way. The issue is factually and conceptually wider than that. In some respects this approach might seem to be less noble (almost everything is banal if compared with free will) but, in the end, the questions that arise might be even more challenging; e.g. the social/mental/technical/biological boundaries of any individual who might be under discussion.

\section{NEUROSCIENCE AND ACCOUNTABILITY: DIFFERENT APPROACHES}

There are various approaches to the impact of neuroscience on the law. One believes that neuroscience could in time overcome ancient illusions (e.g. free will). This position is clearly and cogently expressed thus by Joshua Greene and Jonathan Cohen: “... for the law, neuroscience changes nothing and everything. Free will as we ordinarily understand it is an illusion generated by our cognitive architecture. Retributivist notions of criminal responsibility ultimately depend on this illusion and, if we are lucky, they will give way to consequentialist ones, thus radically transforming our approach to criminal justice" (Greene and Cohen, 2004). Greene and Cohen thus openly declare their acceptance of the theory that neuroscientific findings will have a transformative effect on people's moral perception about free will and responsibility. Other scholars are even more positive. Abigail Baird and Jonathan Fugelsang, for example, point to brain imaging technology as an important opportunity to demonstrate once and for all the cerebral development of adolescents, with the consequent impossibility of considering a teenager as being fully criminally responsible (Baird and Fugelsang, 2004). This is particularly important in the USA context, where only recently the Federal Supreme Court excluded the possibility of a death sentence with reference to an adolescent on trial. Support comes also from Erin O'Hara, who states she is one of a group of scholars who consider that a better knowledge of the brain could help to understand the validity of human behavior theories, thus pragmatically advancing the law (O'Hara, 2004).

The second approach, conversely, incorporates neuroscientific discoveries within pre-existing legal categories. Stephen Morse, the main proponent of this position, explicitly argues that legal and scientific categories will remain separate, even after these new developments in neuroscience. In other words, neuroscience will never be able to tell law who is or is not to be considered criminally responsible: law and science cannot answer each other's questions. Morse coins a term to describe the overestimation of the role of the brain in the commission of a crime: Brain Overclaim Syndrome (Morse, 2004). Similarly, Alan Felthous and Henning Sab hold that brain imaging for assessment of criminal responsibility would not be appropriate, because American jurisprudence does not rest on a premise of free will. Rather, the law sets standards for criminal responsibility and various decisional capacities that relate to psychological functions. Whether brain imaging and other neurosciences can one day provide complete alternative explanations of functions of the will based on natural causation is therefore irrelevant (Felthous and Sab, 2008). Tancredi and Brodie come to similar conclusions, affirming the impossibility of explaining criminal behavior on the basis of a single neuroscientific test (Tancredi and Brodie, 2007).

A third point of view is that put by the neuroscientist David M. Eagleman, who maintains that people are generally not aware of all the factors driving their behavior even if the legal system rests on the assumption that we are practical "reasoners", free to choose how we act. Rather, neural understanding of behaviors will lead to "better prediction of recidivism, a rational basis of sentencing and customized rehabilitation" (Eagleman, 2008). A change in the way of sentencing and practical reasoning may lead to more forward-thinking legislation, in which prison terms are predicated on the perceived risk of recidivism, structuring positive and negative incentives to take better advantage of people's neural mechanism.

\section{BRAIN AND BIOLOGICAL BOUNDARIES}

Although the importance of this debate should not be overlooked, we think that a survey of the technological applications of neuroscience on the human body, and their related impact on the law - even beyond the field of criminal law - would 
be extremely helpful in order to properly focus the issue. A provisional list of applications is the following:

- Brain-machine-web connections and the creation of cyborgs are now less of a futuristic issue given that new organic/synthetic interfaces allow computers to read, interpret and interact with human nerve fibers. This represents new opportunities for people affected by diseases such as muscular dystrophy. Moreover, a few years ago, unforeseen chances opened up for healthy people wanting to improve their level of communication and mental performance.

- Scientific methods of selection could be used by schools or by firms on the basis of specific attitudes revealed by brain scanning tests.

- In recent years it has become possible to ameliorate the mental condition of brain-stressed people: drugs such as Provigil and Ritalin, which make it possible to not perceive fatigue for an extended time, are used by students to improve their scholastic performances.

- The current definition of brain death has moved on from that formulated by the Ad Hoc Committee to examine the definition of Brain Death of Harvard Medical School (1968) and its following revisions. The new neuroscientific technologies may now enable us to refine our comprehension of the residual activity found in a person's brain when no organized neural activity seems to be present. They would be important also in relation to surgical intervention on the human brain.

Overall, this short survey seems to confirm that the impact of neuroscience on responsibility and criminal law is factually and conceptually wider than usually considered. One conclusion is immediately apparent. The impact of neuroscience is plural and fragmented in its various effects, which differ in kind and importance. In some cases neuroscience leads to a reduced detention period (as in the case of juvenile capital punishment in USA cited above) or even to acquittal; in others it might increase the level of legal restrictions on individuals (e.g. in the case of people whose freedom is limited because of their potentially aggressive mental condition). In other cases, however, a deeper knowledge of the mental condition of patients might bring doctors to consider a higher number of patients as eligible for a guardianship decision.

However, considering these areas of the impact of neuroscience on law, it seems to us that the neuro-induced redefinition of the biological and mental boundaries of any individual is the most critical point. Of course this is not new and neuroscience is only the latest reason for reopening the issue. In recent decades, human biological limits look like a field where battles are fought, peace treaties signed and boundary lines drawn. All this, of course, depends on the extensive application of human genetics, new biotechnologies and medical techniques in health services, biological research and society. All human individuals, as biological entities, are deeply affected by these developments.. Advances such as artificial ventilation, new resuscitation techniques, artificial nutrition and hydration have prolonged people's lives. Assisted reproduction techniques have widened the opportunities of bearing children. Furthermore, individuals are given the possibility to radically change their physical state even when there is no disease (at least in traditional terms), such as in the case of transsexuals. The list of biotechnological opportunities grows longer every day with the addition of new items such as genetic manipulation. As a result, the possibility of re-determining human biological limits, and selecting options, is further increased (Santosuosso et al., 2007).

\section{CONCLUSION}

The contribution of neuroscience to the battlefield might be summarized in the following terms. If the question of individual boundaries is given priority, the age-old question of free will may no longer be at the forefront. Furthermore, we may discover that an individual's will is intertwined with those of other people. If so, should we move from the concept of an individual (free) will towards a social group's will? Are associations like this merely temporary? Is immediate opting-out guaranteed? Who is the individual that will opt out? Will it be the "who" that freely decided to join the association?
Or will it be the "new who" that is the result of the experience of association? Are they the same person? In other words, does the individual identity survive the association? Is the free, informed decision to associate a sufficient guarantee? Or should a guardian be appointed in order to assure the freedom of decision (whose?) and respect for the conditions necessary for opting out?

Questions like these, even though not new in philosophical debate (Parfit, 1984), are now on the legal agenda and require a social response. From a legal viewpoint the question might be conceptualized as a matter of sovereignty. In other words, once nature is out of play and is no longer able to tell us what to do or not to do, the question Who has the power and is entitled to draw the boundary line for each individual? becomes crucial. At the moment we do not have a better idea than to entitle and empower each individual.

\section{REFERENCES}

Baird, A. and Fugelsang, J. A. (2004). The emergence of consequential thought: evidence from neuroscience, Phil. Trans. R. Soc. Lond. B 359, 1797-1804.

Eagleman, D. M. (2008). Neuroscience and the law. Houst. Lawyer 16, 37-40.

Felthous, A. R., and Sab, H. (2008). Introduction to this issue: International perspectives on brain imaging and the law. Behav. Sci. Law 26, 1-6.

Glannon, W. (2007). Defining Right and Wrong in Brain Science. Essential Readings in Neuroethics. Dana Press - Dana Foundation Series on Neuroethics, New York, pp. xvii.

Greene, J., and Cohen, J. (2004). For the law, neuroscience changes nothing and everything. Phil. Trans. R. Soc. Lond. B 359, 1775-1785.

Morse, S. (2004). New neuroscience, old problems. Legal implications of brain science, Cerebrum 6, 81-90.

O'Hara, E. A. (2004). How neuroscience might advance the law. Phil. Trans. R. Soc. Lond. B. 359, 1677-1684.

Parfit, D. (1984). Reasons and persons. Oxford, Clarendon.

Santosuosso, A., Sellaroli, V., and Pavone I. (2007). Drawing the boundary lines of humans: in whose bailiwick? Derecho y Religiòn vol. II. 11-36.

Tancredi, L. R., and Brodie, J. D. (2007). The brain and behaviour: limitation in the legal use of functional magnetic resonance imaging. Am. J. Law Med. 33, 294.

Received: 30 June 2009; published online: 23 December 2009.

Citation: Front. Hum. Neurosci. (2009) 3:45. doi: 10.3389/neuro.09.045.2009

Copyright $($ C 2009 Santosuosso. This is an open-access publication subject to an exclusive license agreement between the authors and the Frontiers Research Foundation, which permits unrestricted use, distribution, and reproduction in any medium, provided the original authors and source are credited. 